\title{
Effect of Tree Shade on Coffee Crop Production
}

\author{
Molla Mekonnen Alemu ${ }^{1}$ \\ ${ }^{1}$ United Nations Development Programme, Freetown, Sierra Leone \\ Correspondence: Molla Mekonnen Alemu, Wilkinson 55, Freetown, Sierra Leone. Tel: 232-7906-1001. E-mail: \\ mollamekonnen@gmail.com
}

Received: August 6, $2015 \quad$ Accepted: October 19, 2015 Online Published: October 29, 2015
doi:10.5539/jsd.v8n9p66

\begin{abstract}
Ethiopia is the primary centre of origin and genetic diversity of Arabica coffee plant. Factors that affect the development of plants including coffee are climate, soil type, mulching, shade farming method used, pruning, etc. Amongst the various factors for having a good yield of coffee is growing of shade trees with the coffee plant which has a great contribution on both the life span of the coffee trees and its yield. Many small coffee farms usually grow different species of trees as an integral part of the production system (e.g. fruit and nut trees). This in turn have manifold ecological benefits by serving as windbreaks and shelterbelts, for aesthetic value in residential areas, and more importantly to protect the coffee plants from excessive sun and high temperatures. Dealing with the pruning waste and managing shade trees to maintain at its optimal shade levels (around 40-50\%) could however look a lot of work. Traditionally, all coffee plants were shade grown and most varieties are naturally intolerant of direct sunlight, and desire a canopy of sun-filtering shade trees. This paper is aimed at exploring the benefits of tree shade on coffee life span and yield.
\end{abstract}

Keywords: Ethiopia, coffee, tree, shade

\section{Introduction}

The word "coffee" comes from the name of a region in Ethiopia where coffee was first discovered - 'Kaffa'. The name 'Kaffa' is inherited from the hieroglyphic nouns 'KA' and 'AfA'. 'KA' is the name of God, 'AFA' is the name of earth and all plants that grow on earth. So the meaning of Koffee (Coffee) from its birth-place bells on as the land or plant of God. In addition to this, as a result of the genetic diversity of Ethiopian coffee, botanists and scientists agree that Ethiopia is the centre for the origin, diversification and dissemination of coffee plant (Bayetta, 2001). According to Anon (1999), there are four types of coffee production systems in Ethiopia: forest coffee $(10 \%)$, semi forest coffee $(35 \%)$, garden coffee $(50 \%)$ and plantation coffee $(5 \%)$.

Climatic factors, type of soil, mulching, farm management method, crop production methods, etc. are among the prominent factors that affect the growth and development of plants including coffee. Amongst the various factors for having a good yield of coffee is growing of shade trees with the coffee plant which has a great contribution on both the life span of the coffee trees and its yield.

In many parts of the world, small scale coffee growers' uses multi-purpose trees (e.g. forage trees, fruit, nut trees, etc.) as shade, shelterbelt and windbreaks, for beautifying residential areas, and serve as shelter for coffee plants from excessive sun and high temperatures. However, the management of maintaining optimal shade levels (around $40-50 \%$ ) and dealing with the pruning waste of the plants can also become a lot of work, (Travis and Adel, 2010).

Traditionally, all coffee plants were shade grown and most varieties are naturally intolerant of direct sunlight, and prefer a canopy of sun-filtering shade trees. The trees not only protect coffee from direct sun light, they also mulch the soil with their fallen leaves which helps to protect the soil from excessive temperature and retain soil moisture thereof reducing evaporation. Coffee plantations managed in this traditional manner, as they mimic forests, will also provide a lively habitat which is able to harbor wildlife and different bird species. The birds in turn help to facilitate pollination and serve as a biological insect control for their unceasing foraging. It is therefore from this integrated farming system that the best quality coffee beans are produced. However, as a result of the increased demand for coffee, a higher way of productivity, that is growing coffee plant in the open sun, was developed for coffee farming. This approach is followed by the continual application of chemical fertilizers and pesticides to keep up with the plants' faster growth rate and to make up for the loss of nutrients 
(because of severe soil erosion and removal of nitrogen-fixing trees from the surface).

The increased shift from shade grown to open sun coffee crop production systems has affected the quality of coffee available to most consumers. Apart from that, the drastic shift in the mode of coffee production manifested a severe decline in the density as well as species diversity of migratory birds. For example, a research made in Mexico have found out that, 94-97\% fewer bird species in sun grown coffee than in shade grown coffee farms (Kent et al., 2006). Amidst of the ecological benefits of forest trees for the sustainable and organic production of coffee as well as the benefits in conserving and use of coffee genetic resources, the forest resources are being cleared rapidly from the earth's surface at an alarming rate as a result of deforestation, land use and land cover change. In Ethiopia, deforestation is estimated at 10,000 ha/year in the southwestern coffee growing regions (Mekuria, et. al., 2004). As a result of this the fauna and flora genetic resources of the country are being threatened posing a problem to the sustained development of the country.

\section{Objectives}

The objectives of this article are i) to explore the effect of tree shade on the yield and life span of coffee and ii) highlight multiple impacts of natural resources conservation like forest, land, etc. due the combined effect of coffee production under tree shade.

\section{Methodology}

For the compilation of this articles a set of summaries were drawn in the form of a critical analysis and discussion, by considering a range of awareness of differing arguments, theories and approaches. Guided by the research objective a synthesis and analysis of the related different information and findings which are linked to the theme and rationale of the article were identified and analyzed from various sources.

The paper attempted to justify the scope of the relationship among tree shade and coffee life span and yield by interpreting a number of facts. The review also compared and contrasted the different views and issues of the effect of shade on coffee life span and yield by highlighting exemplary research studies. The analysis also highlighted the research gaps to be addressed in other further research.

\section{Results}

Growing coffee under tree shade is among the prominent agronomic practices in traditional organic coffee growing systems. Growing coffee under a tree shade provides ideal microclimate for growth and production of coffee bushes by damping the diurnal ambient air temperature oscillations. The system is also an ideal way of organic farming as the leaf and other falls of the tree shade will add to the organic matter content of the soil by contributing organic biomass to the litter. As a biological soil and water conservation mechanism, shade trees also minimize soil and water erosion by reducing the intensity of rain reaching the ground. Apart from this, the deep root system of most trees helps facilitating the filtration of rain water into the inner layers of the soil strata and thereof reducing surface run-off of rainwater and at the same time contributes in recharging the ground water. Shade trees likewise reduce evaporation from the land surface and evapotranspiration from plants. Further to creating hostile settings for pests (eg. white stem borer), shade trees are likewise are stated to harbor a range of predatory birds and natural enemies of pests consequently contributing towards their natural and biological control and hence contributing to the organic production of coffee. Shaded coffee plantations compare quite favorably to natural forest as refuges for migratory birds and also have high potential as refugees for the conservation of biodiversity (Perfecto et al., 1996). Furthermore, shade trees can also serve as pathways or stopovers for the migration of animal species between micro-organisms. Under shade trees, there are two ecological functions (energy flow and bio-geo-chemical cycling), both taking place via complex interactions among organisms as well as between organisms and their surrounding physical environment, which in turn will help to stabilize the ecosystem. Therefore, such an agroforestry system of growing coffee under tree shades will enable the natural ecosystem to regulate itself by increasing the fact that coffee crop production in Ethiopia is said to be a natural way of growing coffee and hence organic. Naturally, coffee plants do not tolerate excessive light intensity. Excessive light intensity as indicated by (Kitao et al. 2000), affects plant growth by promoting photo oxidation of chloroplast components which provoke a reduction of productivity of the plant as a result of photo inhibition. However, shade trees were found to reduce the percentage of light intensity reaching coffee bushes. Apart from that, growing coffee under tree shade supports not only for the longer term maintenance of yields from the coffee plant but also reduces periodic over-bearing and subsequent die back of coffee plants. In addition to this, shade is also believed to delay the maturation period of coffee berries, which in turn results in a better bean filling and larger bean size. Indeed, research findings revealed that beans produced from shade grown coffee do have a better quality than those produced from open environments and as a result have higher market value than those grown in an open sun. Among other ecological benefits shade trees are believed to provide 
substantial economic benefit to coffee growers in the form of woody, firewood, edible fruits, etc. This is therefore, a worthy compromise among an acceptable decline in coffee plant productivity and a diversification of revenues from sales of timber products and fruit (for example banana).

In terms creating an ambient microclimate, shade trees have an effect on reducing the maximum and raise the minimum temperatures. In Indonesia, the temperature recorded in shaded fields' average $7^{\circ} \mathrm{c}$ lower during the day and $3^{\circ} \mathrm{c}$ higher during the night, in comparison with open fields precautions were taken to protect against the direct effect of the sun, as a result of shade the yield of coffee is increased by $5 \%$ (Cramer, 1957).

Thomas (1997) claimed that shade is especially valuable when coffee is growing on poor soil or when it is subjected to hot dry spells, he also report that trees specially provide nutrients by digging out to the coffee by their deep root systems.

The rate of photosynthesis is slower under conditions of high light intensity, but it was emphasized that this was only valid for the shrubs outer leaves than those on the inside being shaded by neighboring leaves (self-shading) and therefore under more favorable conditions for carbon assimilation (Rene, 1992).

Shade also has a moderating effect on floral conduction and fruiting by reducing excessive heat from the sun. Shade also reduces evapotranspiration and enables the coffee tree to withstand prolonged periods of moisture stress. In addition to this, the thermo protection for shrubs also continues through the night and contributes to the avoidance of an excessive drop in temperature. In high altitude regions, the difference in temperature between the shaded and the outside environment can be 4 to $5^{\circ} \mathrm{c}$, in the top soil layers, a lower temperature prevents the organic matter from decomposing too rapidly.

Soil under tree shade is also protected from excessive heat, and is therefore less prone to drying out. This will enable the rootlets to continue their nutritive activities in the system. Soils under tree shade are also less sensitive to erosion caused by rain and wind. Since it reduces the availability of sunlight in the ground, tree shade is also believed to suppress the prevalence of weeds. Tree shade also protects the coffee plant from the morning low temperatures in high altitude areas. Tree shades also play a pivotal role in terms of moisture conservation in the given microclimate.

Gordon (1988) also demonstrates die back caused by pseudomonas syringe, which occurs at high altitudes on mount Elgon in Kenya and Uganda, and hot and cold with which it is always associated is worse with low night temperatures and is reduced by growing the coffee under a shade.

\section{Discussion}

Growing coffee under shade is a fundamental principle in coffee growing system as follows:

\subsection{Impact to Micro-Climate}

Shade trees have a pivotal role on creating ambient micro-climate for coffee plantations in particular and for the integral ecological system of the coffee tracts in general. Tree shades basically help to reduce the amount of heat reaching the coffee plant during the day time and protects the coffee plants from the evening and night low temperatures as the trees will serve as a cover and protection, hence contribute for the creation of ambient micro-climate which suits well for the growth and development of coffee bushes. Tree shades also protect coffee plants from destruction by hailstorms and winds by acting as a physical barrier. These benefits are attainable only under mixed shade canopy environments.

\subsection{Contribute to Soil Fertility}

Various researches revealed that, trees contribute biomass (leaf litter, small twigs, etc.), which is among the essential elements of maintaining the organic matter content in the soil. Organic matter rich soils can also can also create conducive environment for many beneficial microorganisms like nitrogen fixers, etc. Nitrogen fixing bacteria help in fixation of atmospheric nitrogen into the soil thereby enriching soil with nitrogen. Besides, organic matter rich soils are also known for enhanced retention of nutrients through its binding effect, which otherwise would have lost by leaching during heavy rains. Various nutrients in the deep strata of soil will also be absorbed by the deep root system of trees and will be availed to the upper layers of the soil in the form of biomass, thus recycling of nutrients from deeper layers is facilitated by the shade trees.

\subsection{Soil and Moisture Conservation}

The top surface layer of soil is always exposed to different sources of erosion. Therefore, conserving the top fertile soil from degradation is an important crop management practice for sustained growth and development of coffee plants. Shade trees help to minimize the erosive power of rainfall by acting as a physical barrier in reducing the intensity of the rain reaching the ground. Shade trees also help in the deep infiltration of rain water 
as a result of their deep rooting system; this in turn will contribute for the recharging of ground water.

Shaded plantations are also well protected against drought effects. The cool temperature above the coffee bushes due to shade, ensure that the loss of soil moisture through evaporation and transpiration is minimized. Besides, the shaded plantations being rich in soil organic matter retain moisture for longer periods during dry months when compared to open conditions.

\subsection{Shade as a Tool for Pest/ Disease Management}

Shade provides efficient biological management tool for the control of major pests and diseases like coffee white stem borer and leaf rust in Arabica coffee. It is well documented that White Stem Borer is active in open patches and these open patches provide ideal conditions for spread of the pest to the neighboring plants. The activity of borer beetles is stifled at cooler temperatures. Thus providing uniform shade is one of the major mechanisms for the effective management of the white stem borer. Besides providing unfavorable conditions for white stem borer, the shade trees are also reported to harbor a variety of predatory birds and natural enemies of white stem borer thus contributing towards natural and biological control of the pest.

\subsection{Reducing the Biennial Bearing in Coffee}

Shade is reported to help not only in the long term maintenance of coffee yields but also to even out erratic yields caused by periodic over bearing and subsequent die back. This is attributed as a result of the fact that shade decreases the amount of light reaching the coffee plants which reduces the potential yields.

\subsection{Shade Trees as Source of Income}

Under careful management system, shade trees provide substantial revenue to the coffee growers in the form of timber, firewood, edible fruits, etc. However, excess opening of shade beyond the recommended level or felling of trees for timber purpose for short term benefits can become counterproductive in the long run. Shade grown coffee has also a strong contribution towards preservation of ecosystem in coffee areas and also conservation of certain bird species.

\subsection{Desirable Trees to Serve as Shade for Coffee}

An ideal shade tree should belong to leguminous family (as they can fix atmospheric nitrogen into soil) and have a tall spreading growth habit, small leaves and should be resistant to wind damage. Considering the above parameters, the trees identified as suitable for coffee plantations are Albizia sp., Ficus sp., Acacia albida, Cordial africana, Leucena leucocephale, Citrus sinensis, Sesbania sesban, Grevilia robusta, Plerocarpus marsupium, Cedrella toona, Artocarpus integrifolia, Artocarpus hirsute, Bischofia javanica, Erythirna lithosperma, Terminalia bellarica, etc. It is desirable to have a mixture of all these trees in a given plantation for providing top canopy shade.

\subsection{Research Gaps}

The intensity of shade in a plantation shall vary depending on climate, growth stage, etc thus; further studies should be done in order to investigate the appropriate shade percentage and the compatibility of shade giving plants and coffee. In addition to these, investigating the severity of competition between shade and coffee plants for both nutrient and water is another line of work to be addressed.

\section{Conclusion and Recommendations}

Shade reduces and stabilizes soil and air temperature; increases and preserves surface soil humidity and also reduces the direct light intensity reaching the coffee plant which has a principal role towards amplified production of coffee. Growing coffee under shade trees is essential not for the sustenance of coffee plantations but also for protecting the environment in the ecologically delicate regions. Coffee growers should maintain and proceed with their traditional coffee growing husbandry in order to optimize their coffee production system and manage their natural resource before the ecosystem will be either completely wiped out or irreversibly ruined due to the current production system, growing coffee in an open sun.

\section{References}

Anonymous. (1999). Coffee Production Systems in Ethiopia Moplaco Trading Co.Ltd.

Baggio, A., Caramori, P., Androcioli Filho, A., \& Montoya, L. (1997). Productivity of Southern Brazilian Coffee Plantations Shaded by Different Stocking of Grevillea robusta, Agroforestry Systems. http://dx.doi.org/10.1023/A:1005814907546

Bayetta, B. (2001). Arabica coffee breeding for yield and resistance to coffee berry disease (Colletotrichum kahawae sp. nov.). Dissertation, University of London, Imperial College Wye, U. K. 
Beer, J., Muschler, R., Kass, D., \& Somarriba, E. (1998). Shade Management in Coffee and Cacao Plantations. Agroforestry Systems, 38, 139-164. http://dx.doi.org/10.1023/A:1005956528316

Cramer. (1957). A Review of literature of coffee research in Indonesia Publ no 15526 editorial, coste Rice 262 pp.

Demel, \& Asefa. (1991). International tree crops journal Academic Publisher printed in Great Britain of 17-27.

Gordon wringly. (1988). coffee crop agriculture services published in USA. 137-140.

Huxley, P. (1970). Some Aspects of the Physiology of Arabica coffee: the central problem and the need for synthesis. In L. C. Luckwill, \& C. V. Cutting (Eds.), Physiology of Tree Crops (pp. 155-268). Academic Press, London, UK.

Idol, T., \& Youkhana, A. (2010). Managing Shade Trees for Coffee Can Benefit the Soil. Hānai‘Ai / The Food Provider. College of Tropical Agriculture and Human Resources, University of Hawai, Manoa.

Kent, D. M., Matthew, J. K., \& Michael, R. M. (2000). Can Shade-Grown Coffee Help Conserve Tropical Biodiversity? A Market Perspective. Endangered Species UPDATE, 17(6), 125-131.

Kirkpatrick, T. (1935). Studies on the ecology of coffee plantations in East Africa, Amani crown Agent, London 66.

Kitao, M., Lie, T. T., Koike, T., Tobita, H., \& Maruyama, Y. (2000). Susceptibility to photo inhibition of three deciduous broad leaf tree species with different successional traits raised under various light regimes. Plant cell environment, 23, 81-89. http://dx.doi.org/10.1046/j.1365-3040.2000.00528.x

Mekuria, T., Neuhoff, D., \& Köpke, U. (2004). The Status of Coffee Production and Potential for Organic Conversion in Ethiopia. University of Bonn, Institute of Organic Agriculture. Bonn, Germany.

Perfecto, I., Rice, R. A., Greenberg, R., \& van der Voort, M. E. (1996). Shade Coffee: A Disappearing Refuge for Biodiversity. Bio Science, 46(8), 598-608. http://dx.doi.org/10.2307/1312989

Rene coste. (1992). coffee the plant and product printed in Hong kong, 97-100.

Thomas, A. (1947). the cultivation and relation of Robusta coffee in Uganda, 65-81.

USDA. (2012). (United States Department of Agriculture). Fact Sheet, An Agroforestry System. Caribbean Area. San Juan, Puerto Rico.

\section{Copyrights}

Copyright for this article is retained by the author(s), with first publication rights granted to the journal.

This is an open-access article distributed under the terms and conditions of the Creative Commons Attribution license (http://creativecommons.org/licenses/by/3.0/). 